\title{
Introduction to Special Issue on "Social Justice in Agricultural and Environmental Economics"
}

\author{
Angelino Viceisza ${ }^{1,2 *}$ (D) and Miesha Williams ${ }^{3}$ \\ ${ }^{1}$ Spelman College, Atlanta, GA, USA; ${ }^{2}$ NBER, Atlanta, GA, USA and ${ }^{3}$ Morehouse College, Atlanta, \\ GA, USA \\ ${ }^{\star}$ Corresponding author. Email: aviceisz@spelman.edu
}

(Received 7 December 2021; accepted 8 December 2021)

If an individual cannot consume harmless and healthy foods in a way that is socially just, then this individual faces the universal threat of food insecurity (Pinstrup-Andersen, 2009); however, microcosmic matters in agriculture may be helpful in finding global solutions. Whereas, addressing food insecurity sheds light on public health problems in weight control, nutritional monitoring, and chronic and life-threatening illnesses (Campbell, 1991; Gunderson and Ziliak, 2015; Seligman et al., 2007, 2010), which are generally attributable to economic disparities (Coleman-Jenson et al. 2018). The COVID-19 pandemic has highlighted social injustices in agriculture and the environment. For example, food insecurity has increased as a result of labor market pressures, leading to joblessness, income losses, and supply chain disruptions (United Nations 2020; Cardoso et al., 2021; Udmale et al., 2020). Moreover, varying aspects of agricultural disparities have warranted much attention because of their global implications for food insecurity (O'Hara and Toussaint, 2021; Power et al., 2020; Battersby, 2020; LiverpoolTasie et al., 2021). In addition, COVID-19 has put environmental resources to task and encouraged concerns regarding value chain production and cross border integration which support a more globally just agricultural existence (Al-Saidi and Hussein, 2021).

To address issues surrounding social justice in agricultural and environmental economics, this special issue brings together seven articles that are organized around two themes. The first set of articles addresses farms, cooperatives, agricultural policies, and the environment. Three of these articles study developing country contexts - Nigeria, Uganda, and Senegal - while the fourth focuses on a developed country context - Japan. The second set of articles study racial and income disparities in food access, obesity, and the environment. All these articles focus on a developed country context - the USA.

Starting with the first theme:

1. Odozi and Oyelere use a nationally representative panel data set for Nigeria from 2010 to 2015, in combination with armed conflict data, to estimate the average effect of exposure to violent conflict on a household's farm labor supply. They find that exposure to violent conflict significantly reduces total family labor supply hours in agriculture. This decline in family labor supply is driven by a significant decline in the household head's total number of hours on the farm.

\footnotetext{
(c) The Author(s), 2021. Published by Cambridge University Press on behalf of the Northeastern Agricultural and Resource Economics Association This is an Open Access article, distributed under the terms of the Creative Commons Attribution licence (https://creativecommons.org/licenses/by/4.0/), which permits unrestricted re-use, distribution, and reproduction in any medium, provided the original work is properly cited.
} 
2. Hill et al. introduce two randomized controlled trial (RCT) interventions aimed at promoting collective commercialization in Ugandan farmer cooperatives: cash on delivery and information on sales. They find that providing cash on delivery increases the probability that a member chooses to sell through the group, and hence the volumes bulked by each group. This increase in volumes appears to have enabled groups to secure higher prices for their produce. No significant effect could be found for providing information on sales.

3. Bernard et al. design an RCT intervention aimed at promoting the functioning of, particularly trust within, farmer cooperatives in Senegal: training group members and/or leaders with respect to pros and cons of collective commercialization. Their design allows identifying both direct treatment effects of having participated in the training and spillover effects on farmers who did not partake. Looking at different measures of trust in leaders' competence and motives and of trust in members, they find that participating in the training significantly enhances both trust in leaders and trust in members. For trust in leaders, they also find a strong spillover effect.

4. Sasaki et al. conduct farm-level simulations on the environmental impacts of agricultural policy instruments in Japan. They find that all types of agri-environmental payments achieve the intended environmental benefits. However, market price support policies do not inevitably increase nitrogen runoff or greenhouse gas emissions. This is because paddy fields themselves tend to function as water purifiers and biodiversity nurseries. They go on to discuss that the direction and magnitude of the policy impacts are an empirical matter which should be considered carefully at the local level.

This first set of articles thus contributes to a vast literature on international agricultural justice issues. This includes smallholder farmers in developing and developed countries who face the added susceptibility of climate change because of the existing institutional and infrastructural challenges (Lindoso et al., 2012; Omerkhil et al., 2020). For example, threats to well-being and food security are increased in these areas because of increased exposure to environmental changes (Alam et al., 2017; FAO et al., 2019; Faisal et al., 2021). This exposure enhances the likelihood of disease, frequency of occurrence and hazard level associated with floods and droughts, reduced crop production and yield, as well as livestock mortality (Faisal et al., 2020, 2021; Harvey et al., 2014; Thornton et al., 2014). When developing countries in particular look to improve agriculture, however, smallholder investment and land ownership can be tricky in certain areas (Wang et al., 2021). So, focusing on those key issues in addition to environmental support can be a key tool for equalizing agricultural development and growth worldwide. This can be especially true for countries facing the resulting issues of the water, food, energy, and waste nexus which are constantly at odds with population control, natural resource availability, sanitation issues (Petrariu et al., 2021), unsustainable consumption, and production patterns (Santeramo and Lamonaca, 2021; Dinu et al., 2020; Istudor et al., 2019). To this end, one goal of this special issue is to address the gaps in international agriculture and environmental disparities in order to highlight social justice, or injustice, as a global problem.

Turning to the second theme of articles on racial and income disparities in the USA:

5. Ware et al. examine whether racial disparities exist in travel distances and travel times to grocery stores using data from Seattle, WA. They find that disparities in travel distance and travel time to supermarkets vary with the percentage of specific 
racial and ethnic populations. Greater Asian populations in a census tract are associated with shorter travel distance to the grocery store, low income, and low vehicle access. For the Hispanic population, a greater percentage in a census tract increases the predicted travel distances and travel times to grocery stores. Greater income in tracts with more Hispanic population is associated with a shorter distance, and those tracts with more Asian population are associated with a longer distance, possibly due to cultural differences in diet.

6. Durfee et al. use baseline data from an observational study to estimate the determinants of racial and gender disparities in obesity. Samples of low-income workers in Minneapolis, $\mathrm{MN}$, and Raleigh, $\mathrm{NC}$, reveal that respondents in Minneapolis have lower body mass indices (BMIs) than respondents in Raleigh. There are large, statistically significant race and gender effects in estimates of BMI that explain most of the disparity between the two cities. Accounting for intersectionality - the joint impacts of being Black and a woman - reveals that almost all the BMI gaps between Black women in Minneapolis and Raleigh can be explained by age and education differences.

7. Mohr et al. review articles identifying Superfund sites in three national newspapers from 1982 to 1984 . They find that articles almost never identify the race of nearby residents. Based on sites receiving disproportionate coverage, readers might conclude that Superfund generally affected White, working-class families, but results do not support this narrative. In a pooled sample, neither race nor income predicts the number of times a site gets mentioned. When the sample is partitioned by newspaper or by each newspaper's coverage of nearby sites, a positive relationship emerges between the proportion of Hispanic or non-White residents and the number of articles about a site. They go on to discuss this apparent contradiction.

This second set of articles thus contributes to a vast literature on racial and income disparities, particularly as those pertain to food access, diet and obesity, and environmental justice. In fact, behavioral food demands and agricultural supply chains have become important for the social justice perspective in agriculture. If teaching healthy food habits has a limited impact on sustainable demand for healthy food (Janda et al. 2021), then areas where food worries, supplemental assistance, poor access to healthy food options, and environmental health concerns are insurmountable experience institutional barriers to agricultural demand (Clay and Rogus, 2021; Wolfson and Leung CW, 2020 (1 and 2); Niles et al. 2020; Rosas et al. 2022). On the other hand, resolving the agricultural supply chain issue requires addressing other institutional factors. Such factors include increased and localized availability of digital shopping, farmers' markets as well as grocery stores with fruits and vegetables in urban areas (Cummins et al. 2020; $\mathrm{Hu}$ et al., 2021; Brown and Miller, 2008). Meanwhile, the aim of socially and environmentally effective supply chain is to improve accessibility to agriculture as well as encourage fresh food options and overall good health in circular food economies (Hu et al., 2021; Li et al., 2014) without labor supply concerns (Varshney et al., 2020; Cardoso et al., 2021), especially where the end-product is crucial to low-income areas (Allcott et al., 2017). Some localized innovations of urban food economies in the USA relate food to green infrastructure, training and testing facilities for urban agriculture, and improved public health outcomes ( $\mathrm{Li}$ et al., 2014). In addition, instituting circular food economies can demand new technologies, new forms of knowledge production (Rip, 200), sociotechnical change (Kemp et al., 1998), and new institutions (Henrysson and Hendrickson, 2021). In this case, this special issue's stance is that improvements in food economies are inextricably linked to the 
environmental, physical social, and cultural context of local communities (Stuiver and O'hara, 2021) and can undoubtedly improve agricultural realities in the USA.

In addition, environmental injustice has contributed to the lack of good health and hardy well-being for Blacks, Hispanics, and other racial minorities in the USA. To this end, the special issue addresses how localized waste can encourage a platform for social justice reform as well. Since the late 1970s and early 1980s, relationships among, race, poverty, and environmental contaminants have been nationally recorded and studied (Bullard, 1983; US GAO, 1983; Commission for Racial Justice, United Church of Christ). Legislative inclusion, thoughtful exposures to contaminants, and improved housing options can support disproportionate exposure to environmental pollutants (Banzhaf et al., 2019). To further expose the utilization of environmental justice among all races, this special issue offers a study on race in relation to Superfund.

In conclusion, the articles in this special issue suggest that agricultural, food, and environmental disparities continue to exist, both in developing and developed country contexts. Moreover, such disparities are associated with race, gender, and income. So, additional research is needed to further understand the types of policies that would structurally address social justice issues generally, but particularly when it concerns agriculture and the environment.

Acknowledgments. We are grateful to the Northeast Agricultural and Resource Economics Association (NAREA) board, particularly Sarah Jacobson and Richard "Max" Melstrom (Agricultural and Resource Economics Review editor) for conceiving this special issue. We are also grateful to several anonymous referees for providing feedback on the manuscripts. Miesha Williams is thankful to the Sol Price School of Public Policy at University of Southern California, where she was on leave while some of this work was completed, for their support.

Funding Statement. We would like to thank the United States Department of Agriculture's National Institute of Food and Agriculture for funding the open access publication of this special issue through grant number 2021-67023-34646 titled "Social Justice in Agricultural and Environmental Economics."

\section{References}

Alam, M.M., C. Siwar, B.A. Talib, and A.N. Wahid. 2017. "Climatic changes and vulnerability of household food accessibility: A study on Malaysian east coast economic region." International Journal of Climate Change Strategies and Management 9(3): 387-401.

Allcott, H., R. Diamond, and J.P. Dubé. 2017. "The geography of poverty and nutrition: Food deserts and food choices across the United States." National Bureau of Economic Research.

Al-Saidi, M., and H. Hussein. 2021. "The water-energy-food nexus and COVID-19: Towards a systematization of impacts and responses." Science of The Total Environment 779. https://oi.org/10.1016/j. scitotenv.2021.146529

Banzhaf, S., L. Ma, and C. Timmins. 2019. "Environmental justice: The economics of race, place, and pollution." Journal of Economic Perspectives 33(1): 185-208.

Battersby, J. 2020. "South Africa's lockdown regulations and the reinforcement of anti-informality bias." Agriculture and Human Values 37: 543-544.

Brown, C. and S. Miller. 2008. "The impacts of local markets: a review of research on farmers markets and community supported agriculture (CSA)." American Journal of Agricultural Economics 90(5): 1298-1302.

Bullard, R.D. 1983. "Solid waste sites and the black Houston community." Sociological Inquiry 53(2-3): 273-288.

Campbell, C.C. 1991. “Food insecurity: a nutritional outcome or a predictor variable?” Journal of Nutrition 121(3): 408-415.

Cardoso, B., L. Cunha, A. Leiras, P. Gonçalves, H. Yoshizaki, I. de Brito Junior, and F. Pedroso. 2021.

"Causal impacts of epidemics and pandemics on food supply chains: a systematic review." Sustainability 13(17): 9799. 
Clay, L.A. and S. Rogus. 2021. "Food access worries, food assistance use, purchasing behavior, and food insecurity among New Yorkers during COVID-19." Frontiers in Nutrition 8. https://doi.org/10.3389/ fnut.2021.647365.

Coleman-Jensen, A., M.P. Rabbitt, C.A. Gregory, A. Singh. 2018. Household Food Security in the United States in 2017, ERR-256, U.S. Department of Agriculture, Economic Research Service..

Commission for Racial Justice, United Church of Christ (UCC). 1987. Toxic Wastes and Race in the United States: A National Report on the Racial and Socio-Economic Characteristics of Communities with Hazardous Waste Sites. https://www.nrc.gov/docs/ML1310/ML13109A339.pdf (accessed December 17, 2021)

Cummins, S., N. Berger, L. Cornelsen, J. Eling, V. Er, R. Greener, et al. 2020. "COVID-19: impact on the urban food retail system and dietary inequalities in the UK." Cities \& Health. https://doi.org/10.1080/ 23748834.2020 .1785167$.

Dinu, M., S.R. Pătărlăgeanu, R. Petrariu, M. Constantin, and A.-M. Potcovaru. (2020). "Empowering sustainable consumer behavior in the EU by consolidating the roles of waste recycling and energy productivity." Sustainability 12(23): 9794. https://doi.org/10.3390/su12239794.

Faisal, M., A. Abbas, C. Xia, M.H. Raza, S. Akhtar, M.A. Ajmal, et al. 2021. "Assessing small livestock herders' adaptation to climate variability and its impact on livestock losses and poverty." Climate Risk Management 34: 100358.

Faisal, M., X. Chunping, S. Akhtar, M.H. Raza, M.T.I. Khan, and M.A. Ajmal. 2020. "Modeling smallholder livestock herders' intentions to adopt climate smart practices: An extended theory of planned behavior." Environmental Science and Pollution Research 27(31): 39105-39122.

FAO, IFAD, UNICEF, WFP and WHO. 2019. The State of Food Security and Nutrition in the World 2019. Safeguarding against economic slowdowns and downturns. Rome, FAO.

Gundersen, C., and J.P. Ziliak. 2015. "Food insecurity and health outcomes." Health Affairs 34(11): $1830-1839$.

Harvey, C.A., Z.L. Rakotobe, N.S. Rao, R. Dave, H. Razafimahatratra, R.H. Rabarijohn, et al. 2014. "Extreme vulnerability of smallholder farmers to agricultural risks and climate change in Madagascar." Philosophical Transactions of the Royal Society B: Biological Sciences, 369(1639): 20130089.

Henrysson, M., and C.Y. Hendrickson. 2021. Scope for circular economy model in urban agri-food value chains. In "Sustainable Consumption and Production, Volume II" (pp. 75-97). Palgrave Macmillan, Cham, Switzerland.

Hu, X., L.W. Clarke, and K. Zendehdel. 2021. "Farmers' market usage, fruit and vegetable consumption, meals at home and health-evidence from Washington, DC." Sustainability 13(13): 7437.

Istudor, N., R.A. Ion, I.E. Petrescu, and A. Hrebenciuc. 2019. "Agriculture and the Twofold relationship between food security and climate change. Evidence from Romania." Amfiteatru Economic 21(51): 285-293.

Janda, K.M., N. Ranjit, D. Salvo, A. Nielsen, N. Akhavan, M. Diaz, et al. 2021. "A multi-pronged evaluation of a healthy food access initiative in central Texas: study design, methods, and baseline findings of the FRESH-Austin evaluation study." International Journal of Environmental Research and Public Health 18(20): 10834

Kemp, R., J. Schot, and R. Hoogma. 1998. "Regime shifts to sustainability through processes of niche formation: the approach of strategic niche management." Technology Analysis \& Strategic Management 10(2): 175-198.

Li, D., E. Bou-Zeid, and M. Oppenheimer. 2014. "The effectiveness of cool and green roofs as urban heat island mitigation strategies." Environmental Research Letters 9(5): 055002.

Lindoso, D.P., J.D. Rocha, N. Debortoli, I.C.I. Parente, F. Eiró, M. Bursztyn, and S. Rodrigues Filho. 2012. "Indicators for assessing the vulnerability of smallholder farming to climate change: The case of Brazil's semi-arid northeastern region." International Policy Centre for Inclusive Growth (IPC - IG). One Pager No. 163. https://ipcig.org/sites/default/files/pub/en/IPCOnePager163.pdf (accessed December 17, 2021).

Liverpool-Tasie, L.S.O., T. Reardon, and B. Belton. 2021. "Essential non-essentials": COVID-19 policy missteps in Nigeria rooted in persistent myths about African food supply chains." Applied Economic Perspectives and Policy, 43(1): 205-224.

Morseletto, P. 2020. "Restorative and regenerative: Exploring the concepts in the circular economy." Journal of Industrial Ecology, 24(4): 763-773.

Niles, M.T., F. Bertmann, E.H. Belarmino, T. Wentworth, E. Biehl, and R. Neff. 2020. "The early food insecurity impacts of COVID-19." Nutrients 12(7): 2096. 
O'Hara, S. and E.C. Toussaint. 2021. "Food access in crisis: Food security and COVID-19." Ecological Economics 180: 106859.

Omerkhil, N., T. Chand, D. Valente, J.M. Alatalo, and R. Pandey. 2020. "Climate change vulnerability and adaptation strategies for smallholder farmers in Yangi Qala District, Takhar, Afghanistan." Ecological Indicators 110: 105863.

Petrariu, R., M. Constantin, M. Dinu, S.R. Pătărlăgeanu, and M.E. Deaconu. 2021. "Water, energy, food, waste nexus: between synergy and trade-offs in Romania based on entrepreneurship and economic performance." Energies 14(16): 5172

Pinstrup-Andersen, P. 2009. "Food security: definition and measurement." Food Security 1(1): 5-7.

Power, M., B. Doherty, K. Pybus, and K. Pickett. 2020. "How COVID-19 has exposed inequalities in the UK food system: The case of UK food and poverty." Emerald Open Research, 2.

Rip, A. 2000. "Fashions, lock-ins and the heterogeneity of knowledge production." In: Jacob, M. and T. Hellstrom (eds.), The Future of Knowledge Production in the Academy (pp. 28-39). Society for Research into Higher Education \& Open University Press.

Rosas, R., F. Pimenta, I. Leal, and R. Schwarzer. (2022). "FOODLIT-tool: Development and validation of the adaptable food literacy tool towards global sustainability within food systems." Appetite 168:105658. https://doi.org/10.1016/j.appet.2021.105658

Santeramo, F.G. and E. Lamonaca. 2021. "Food loss-food waste-food security: a new research agenda." Sustainability 13(9): 4642.

Seligman, H.K., A.B. Bindman, E. Vittinghoff, A.M. Kanaya, and M.B. Kushel. 2007. "Food insecurity is associated with diabetes mellitus: results from the National Health Examination and Nutrition Examination Survey (NHANES) 1999-2002." Journal of General Internal Medicine 22(7): 1018-1023.

Seligman, H.K., B.A. Laraia, and M.B. Kushel. 2010. "Food insecurity is associated with chronic disease among low-income NHANES participants." Journal of Nutrition 140(2): 304-310.

Stuiver, M. and S. O'hara. 2021. "Food connects Washington DC in 2050-a vision for urban food systems as the centerpieces of a circular economy." Sustainability 13(14): 7821.

Thornton, P.K., P.J. Ericksen, M. Herrero, and A.J. Challinor. 2014. "Climate variability and vulnerability to climate change: a review." Global Change Biology 20(11): 3313-3328.

Udmale, P., I. Pal, S. Szabo, M. Pramanik, and A. Large. 2020. "Global food security in the context of COVID-19: A scenario-based exploratory analysis." Progress in Disaster Science, 7, 100120.

United Nations (UN). (2020). Policy Brief: The Impact of COVID-19 on Food Security and Nutrition. https://www.un.org/sites/un2.un.org/files/sg_policy_brief_on_covid_impact_on_food_security.pdf (accessed May 12, 2021).

US General Accounting Office (US GAO). 1983. Siting of Hazardous Waste Land-Fills and their Correlation with Racial and Economic Status of Surrounding Communities. http://archive.gao.gov/ d48t13/121648.pdf (accessed December 17, 2021).

Varshney, D., D. Roy, and J.V. Meenakshi. 2020. "Impact of COVID-19 on agricultural markets: assessing the roles of commodity characteristics, disease caseload and market reforms." Indian Economic Review 55(1): 83-103.

Wang, Y., A. Sarkar, L. Ma, Q. Wu, and F. Wei. 2021. "Measurement of investment potential and spatial distribution of arable land among countries within the 'Belt and Road Initiative'." Agriculture 11(9): 848.

Wolfson, J.A. and C.W. Leung. 2020. "Food insecurity and COVID-19: disparities in early effects for US adults." Nutrients 12(6): 1648.

Wolfson, J.A. and C.W. Leung. 2020. "Food insecurity during COVID-19: an acute crisis with long-term health implications." American Journal of Public Health 110: 1763-1765.

Cite this article: Viceisza, A. and M. Williams. 2021. "Introduction to Special Issue on 'Social Justice in Agricultural and Environmental Economics." Agricultural and Resource Economics Review 50, 395-400. https://doi.org/10.1017/age.2021.28 